\title{
EXPERIMENTAL RESEARCH ON THE MECHANICAL PROPERTIES OF SHEAR CONNECTORS FOR COMPOSITE BEAM BRIDGE
}

\author{
Shi-bo Zhang ${ }^{1}$, Rong-hui Wang ${ }^{2}$, Zhou $\mathrm{Li}^{3}$, \\ ${ }^{1}$ School of Civil Engineering and Transportation, South China University of Technology \\ (bridge007@sogou.com) \\ ${ }^{2}$ School of Civil Engineering and Transportation, South China University of Technology \\ ${ }^{3}$ School of Civil Engineering and Transportation, South China University of Technology
}

\begin{abstract}
Two 1:2 reduced-scale model tests with different types of shear connectors are conducted to study the mechanical properties of shear connectors for a composite beam under complex stress conditions. The strain of the shear connector and relative slipping on the steel-concrete interface of the rigid shear connector model and flexible shear connector model under the same boundary conditions is measured. Responses of two types of shear connectors under three different load cases are compared. The test results show that the ultimate bearing capacity of concrete is the key factor of relative slipping on the steel-concrete interface, and differences between rigid and flexible shear connectors are large.
\end{abstract}

Keywords: Mechanical properties, Shear connectors, Composite beam, Model test

\section{INTRODUCTION}

The steel-concrete composite beam bridge is an advantageous bridge style because it takes full advantage of both steel's tensile properties and concrete's compression properties. These two materials are connected by shear connectors in order to transfer shear force on the interface between the steel beam and concrete slab. Good performance of the shear connectors can allow the steel beam and concrete slab bear the load together. Different shear connector types and arrangements afford different shear resistance, which dominates the relative slipping between the steel beam and concrete slab and affects the bearing capacity of the composite beams (see [1]).

The shear bearing capacity of shear connector is easy to calculate (see [2]), but the withdrawal capacity of the shear connectors often requires experimental research to be done because it is difficult to be solved with the general mechanical method (see [3]). Studies on various issues concerning experimental research on shear connectors have been reported. Dennis Lam et.al (see [4]) proposed an effective numerical model using the finite element method to simulate the push-off test and performed parametric studies to investigate varia- 
tions in concrete strength and shear stud diameter. Cem Topkaya et.al (see [5]) proposed a new push-out test to study the composite shear stud strength at early concrete ages. Test results revealed that shear transfer is achieved at very early concrete ages. Ellobody $\mathrm{E}$ and Young B (see [6]) studied the structural performance of shear connection in composite beams with profiled steel sheeting; an accurate and efficient nonlinear finite element model was developed to study the behavior of headed stud shear connectors welded through-deck. Kim YH et.al (see [7]) performed a series of push-out tests to evaluate the performance of several existing shear connectors. Results show that the perforated shear connector with flange head is superior to existing shear connectors such as a general headed stud, perfobond, etc. It is efficient as a rigid shear connector. Kim HY (see [8]) investigated the behavior of steel-concrete composite bridge decks with perfobond ribs through push-out, full-scale flexural, and deckto-girder connection tests. Test results confirmed the effect of perfobond ribs.

Mechanical properties of shear connectors for the composite beam under complex stress condition are studied in detail through two model tests. The models are designed based on a prototype of the three spans of the pre-stressed steel-concrete composite beams bridge in Guangzhou with the main span length of $50+70+60 \mathrm{~m}$. Load-Relative slipping behavior and the shear capacity of the shear connector in composite beam are obtained from the experimental model test including three different load cases: horizontal loading, vertical loading, and a combination of horizontal loading and vertical loading. The results presented in this paper are useful as references for future research and designs of shear connectors in composite beams.

\section{MODEL DESIGN}

Two model tests are conducted. One uses shear studs as the shear connector, which is labeled Model 1, the other uses profiled sheeting as the shear connector, which is labeled Model 2. Design parameters of the two models are the same except the structural type and arrangement of the shear connector. In these two models, the section of steel box girder is $1000 \mathrm{~mm}$ high, $2000 \mathrm{~mm}$ long, and $850 \mathrm{~mm}$ wide. The section of the concrete slab is 2000 $\mathrm{mm}$ long and $4250 \mathrm{~mm}$ wide. The base of the steel box girder and the top of the concrete slab were connected by an embed bolt. Materials of the model adopt 16Mnq steel, C60 concrete, and HRB335 reinforced bar (see [9]). Vertical plans of the model and loading device are shown in Figure 1. The geometric and physical similarity relation between the model and prototype is listed in Table 1.

Table 1 . Geometry and physical similarity ratio (model/ prototype)

\begin{tabular}{cccccc} 
item & size & material parameter & load & stress & strain \\
\hline similarity ratio & $1 / 2$ & $1 / 1$ & $1 / 4$ & $1 / 1$ & $1 / 1$ \\
\hline
\end{tabular}




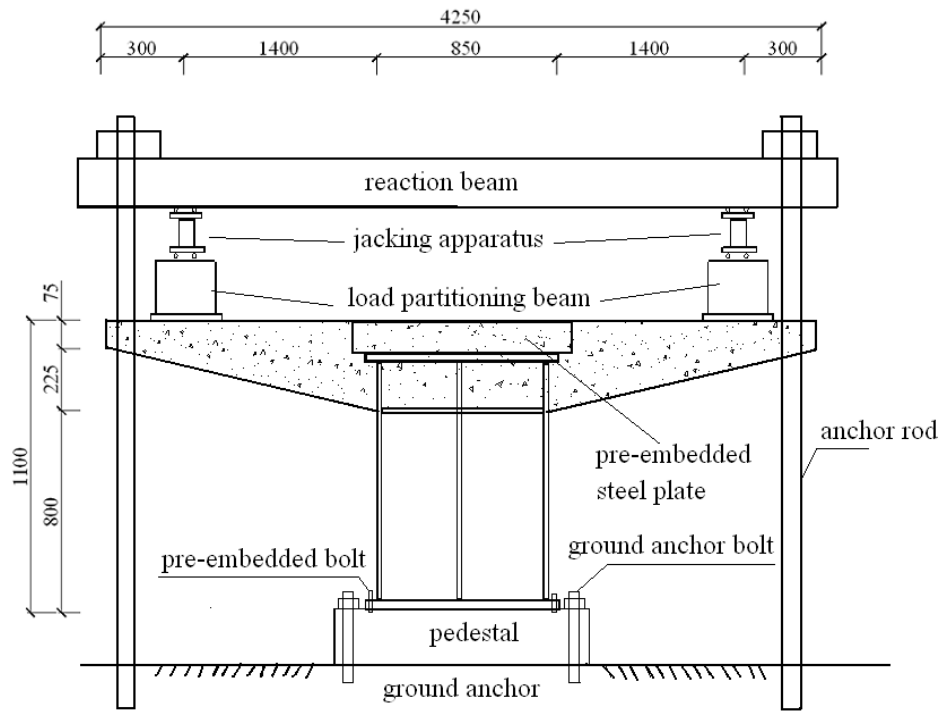

Figure 1. Vertical plan of model and loading device

\subsection{Shear connector arrangement}

In Model 1, the arrangement of shear studs, which are $11 \mathrm{~mm}$ diameter $\times 60 \mathrm{~mm}$ long, is 5 rows and 10 lines with the grid of $200 \times 200 \mathrm{~mm}$. In Model 2, the arrangement of profiled sheeting, which is $50 \mathrm{~mm}$ long $\times 4.5 \mathrm{~mm}$ thickness, is 3 rows and 7 lines with the grid of $300 \times$ $300 \mathrm{~mm}$. Both of the two models have the same steel ratio of the shear connector. The areas of the two kinds of shear connector are: $A_{n}=4751.7 \mathrm{~mm}^{2}$ and $A_{c}=4725.0 \mathrm{~mm}^{2}$, respectively, so it can be considered equal.

\subsection{Loading procedure}

There are three kinds of load cases in the model test: horizontal loading, vertical loading, and a combination of horizontal and vertical loading. For horizontal loading, the load applied to the studs model has no specific direction, but the load applied to the profiled sheeting model is specified from the direction of the mouth of the channel beam. The horizontal load of the two models is loaded from $0 \mathrm{kN}$ to $100 \mathrm{kN}$ gradually. For vertical loading, there are five loading steps from $0 \mathrm{kN}$ to $50 \mathrm{kN}$ at every $10 \mathrm{kN}$ and the loading is repeated three times. For the combination of horizontal and vertical loading, the horizontal load of the two models is stabilized at $100 \mathrm{kN}$ and the vertical load of the two models is loaded from $0 \mathrm{kN}$ at a separation of $10 \mathrm{kN}$ until the models fail.

\subsection{Measuring-point arrangement}

Six strain gages are affixed on the surface of the concrete slab, six high performance reinforcement meters are affixed on the surface of the reinforced bars, and eight strain gages are affixed on the surface of horizontal baffle of steel box girder in each model. Moreover, 
fifty BTM strain meters are affixed on the shear studs in Model 1 and forty-two 120-3AA strain gages are affixed on the profiled sheeting in Model 2.

\section{SUMMARY AND DISCUSSION OF THE RESULTS}

\subsection{The strain of shear connector}

Six strain gages are affixed on the surface of the concrete slab, six high performance reinforcement meters are affixed on the surface of the reinforced bars, and eight strain gages are affixed on the surface of horizontal baffle of steel box girder in each model. Moreover, fifty BTM strain meters are affixed on the shear studs in Model 1 and forty-two 120-3AA strain gages are affixed on the profiled sheeting in Model 2.

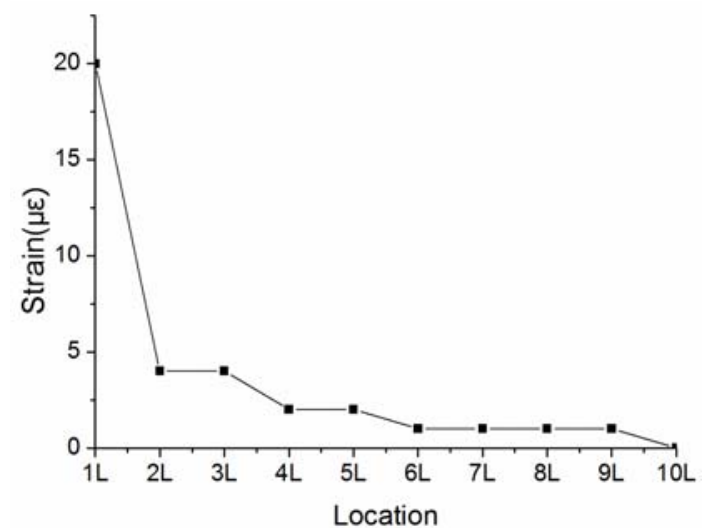

Figure 2. The average axial strain of shear studs under horizontal loading in each row

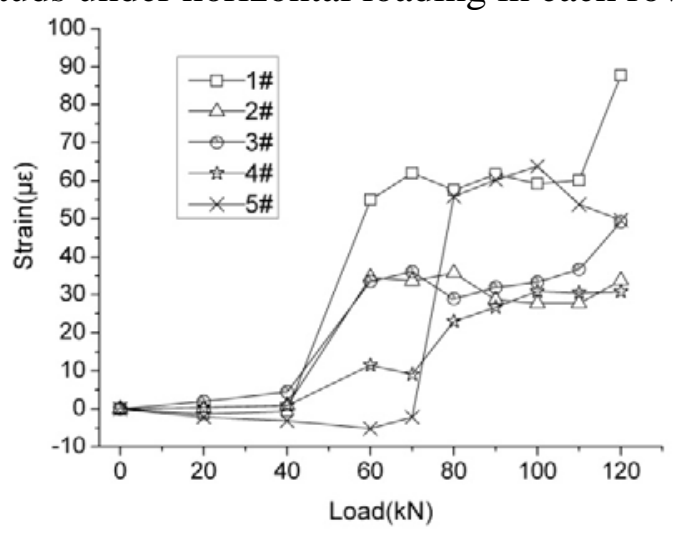

Figure 4. The average axial strain of shear studs under horizontal and vertical loading in each row

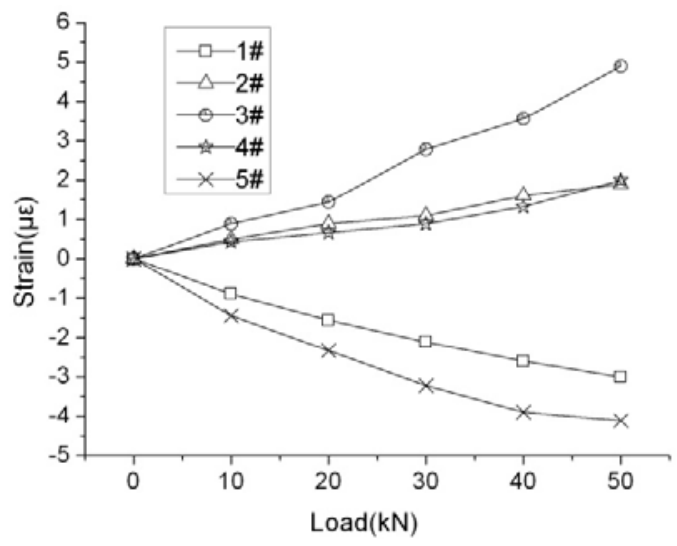

Figure 3. The average axial strain of shear studs under vertical loading in each row

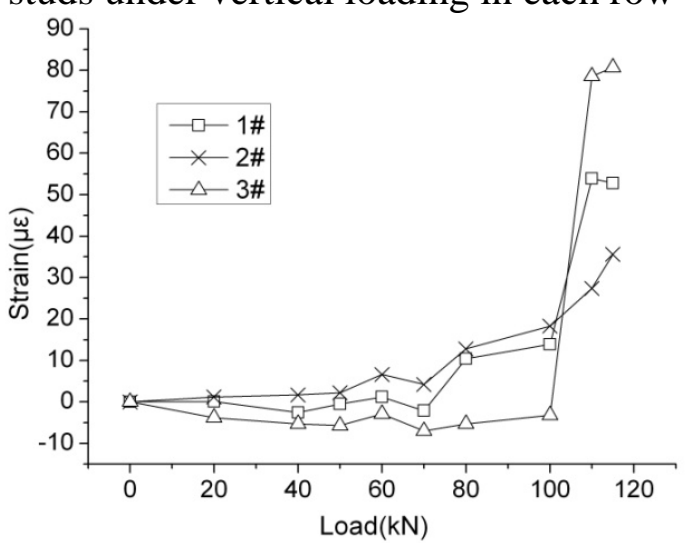

Figure 5. The average axial strain of profiled sheeting under horizontal andvertical loading in each row

Shear connectors are divided into 5 rows (labeled $1 \#$ and $2 \# . . .5 \#$ from left to right) and 10 lines (labeled 1L and 2L... 10L from front to back) in Model 1 and are divided into 3 rows (labeled 1\#, 2\#, 3\# from left to right) in Model 2. The test results and discussions are as follows:

(1) Under horizontal loading, the regularity of the axial strain of shear studs can be found (see Figure.2) in Model 1. The axial strain of shear studs of the first line (nearly the loading point) is bigger than that of the rest, it decreases from the first line to the fifth line. 
The rest (far) can be neglected. The regularity of the axial strain of profiled sheeting cannot be found in Model 2 because the value of the strain is very small.

(2) Under vertical loading (no larger than $50 \mathrm{kN}$ ), shear studs of the \#1 and \#5 rows are in tension while that of rows \#2 \#4 are in compression in Model 1. The profiled sheeting of the \#1 and \#3 rows are in tension while that of the \#2 row is in compression in Model 2. The axial strains of two kinds of shear connectors has linear relationship with the load, but the value of that is very small (see Figure.3).

(3) Under the combination of horizontal and vertical loading, when the horizontal load is stabilized at $100 \mathrm{kN}$ and about $80 \mathrm{kN}$ of the vertical load is applied to shear studs in Model 1 while about $110 \mathrm{kN}$ vertical load is applied to the profiled sheeting in Model 2, tiny cracks appear on the concrete.Then the stress of the shear connector increases rapidly. Finally, all shear connectors are in tension.

(4) Under the combination of horizontal and vertical loading, when the horizontal load is stabilized at $100 \mathrm{kN}$ and before the vertical load reach $100 \mathrm{kN}$, the strain of the two kinds of shear connectors increase slowly at the beginning of destruction. The axial stress of profiled sheeting does not exceed 18.0 MPa and the axial stress of shear studs is between 5.0 MPa and 34.0 MPa when the model has destructed (see Figure.4 and Figure.5).

\subsection{Test results of relative slipping on the steel-concrete interface}

Under horizontal loading, the relative slipping between the concrete slab and box girder is very small. When horizontal loading is up to $100 \mathrm{kN}$, the relative slipping on the steel-concrete interface is $0.18 \mathrm{~mm}$ in Model 1 and $0.15 \mathrm{~mm}$ in Model 2. A linear relationship between the relative slipping and the load is shown on the Load-relative curve in two test models. Moreover, there are no obvious cracks and the slipping can recover when the load is removed. Figure.6 presents the relationship curve between the load and the relative slipping in Model 2.

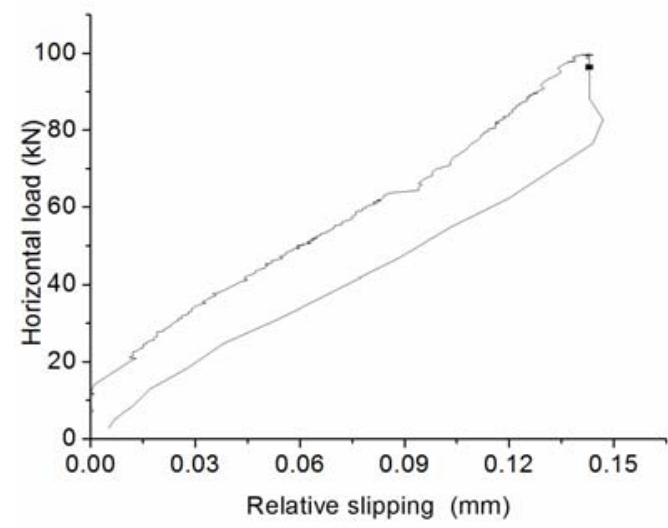

Figure 6. Load-relative slipping curve (model 2)

\section{CONCLUSIONS}

This paper takes the three spans of the continuous composite beams bridge in Guangzhou as a background and conducts experimental research on two 1:2 reduced-scale test models with different shear connectors. The main conclusions are as follows: 
(1) The ultimate bearing capacity of reinforced concrete is the key factor to the relative slipping on the steel-concrete interface under complex stress conditions, and the relative slipping increases rapidly after concrete cracks.

(2) Both rigid and flexible shear connectors can effectively resist load, but the model of profiled sheeting has better slip resistant performance and recovery performance compared to the model of shear studs. The main reason is that profiled sheeting has a stronger restriction to concrete for its big stiffness when the strength of concrete is close to the ultimate strength.

(3) Under $100 \mathrm{kN}$ horizontal loading, the relative slipping is $0.18 \mathrm{~mm}$ on the steelconcrete interface in Model 1 while the relative slipping is $0.15 \mathrm{~mm}$ in Model 2. It indicates that the rigid shear connector can reduce the relative slipping on the steel-concrete interface under the same load.

(4) In the same steel ratio of the shear connector, the withdrawal resistance of profiled sheeting is greater than that of shear studs while the axial stress of profiled sheeting is smaller than that of shear studs.

\section{REFERENCES}

[1] Zhan YL, Zhao RD, Mao XM, "Comparison of the loading capacity of shear connectors in steel-concrete composite structures”. Building Science Research of Sichuan, 6, 16-19, 2006. (in Chinese).

[2] Nie JG, Tan Y, Wang HQ, "Strength of stud shear connectors in composite steel HC beams”. Journal of Tsinghua University (Science and Technology), 12, 94-97, 2006. (in Chinese)

[3] Fang ZZ, Zheng ZQ, "Experimental study on the prestressed steel-concrete composite continuous beams with different degree of shear connection”. Journal of Fuzhou University (Natural Sciences Edition), 3, 343-348, 2002. (in Chinese).

[4] D.Lam, Ellobody E, "Behavior of headed stud shear connectors in composite beam." Journal of Structural Engineering, 1, 96-107, 2005.

[5] Cem Topkaya, Yura Joseph A. Williamson Eric B, “Composite shear stud strength at early concrete ages”. Journal of Structural Engineering, 6, 952-960, 2002

[6] E. Ellobody, Young B, "Performance of shear connection in composite beams with profiled steel sheeting”. Journal of Constructional Steel Research, 7, 682-694, 2006

[7] Kim YH, You SK, Jung JH. et al, "An experimental study on the shear behavior of perforated shear connector with flange head”. Fracture and Strength of Solids Vi, Pts 1 and 2, 306-308, 1349-1354, 2006.

[8] Kim HY, Ju JY, "Experimental investigation on behaviour of steel-concrete composite bridge decks with perfobond ribs”. Journal of Constructional Steel Research, 5, 463-471, 2006.

[9] Ministry of Communications of the People’s Republic of China, "JTG D62-2004 Code for design of highway reinforced concrete and prestressed concrete bridges and culvert”. China Communications Press, Beijing, 2004. 